\title{
Exploiting electric heat pump flexibility for renewable generation matching
}

DOI:

10.1109/PTC.2017.7981266

\section{Document Version}

Accepted author manuscript

Link to publication record in Manchester Research Explorer

\section{Citation for published version (APA):}

Zhang, L., Chapman, N., Good, N., \& Mancarella, P. (2017). Exploiting electric heat pump flexibility for renewable generation matching. In PowerTech, 2017 IEEE Manchester https://doi.org/10.1109/PTC.2017.7981266

\section{Published in:}

PowerTech, 2017 IEEE Manchester

\section{Citing this paper}

Please note that where the full-text provided on Manchester Research Explorer is the Author Accepted Manuscript or Proof version this may differ from the final Published version. If citing, it is advised that you check and use the publisher's definitive version.

\section{General rights}

Copyright and moral rights for the publications made accessible in the Research Explorer are retained by the authors and/or other copyright owners and it is a condition of accessing publications that users recognise and abide by the legal requirements associated with these rights.

\section{Takedown policy}

If you believe that this document breaches copyright please refer to the University of Manchester's Takedown Procedures [http://man.ac.uk/04Y6Bo] or contact uml.scholarlycommunications@manchester.ac.uk providing relevant details, so we can investigate your claim.

\section{OPEN ACCESS}




\title{
Exploiting Electric Heat Pump Flexibility for Renewable Generation Matching
}

\author{
Lingxi Zhang*, Nick Chapman, Nicholas Good, Pierluigi Mancarella \\ School of Electrical and Electronic Engineering, The University of Manchester \\ Manchester, United Kingdom \\ *lingxi.zhang@manchester.ac.uk
}

\begin{abstract}
With the increasing penetration of renewable energy sources in the modern electric grid, it becomes more technically difficult and costly for system operators to balance generation and demand as traditional providers of flexibility (i.e., flexible generation) become uneconomic. Therefore new sources of flexibility are needed to maintain reliable operation. Flexible demand, including from electric heat pump (EHP) resources, is one source of flexibility which can be utilised to cope with the uncertainty of renewable generation by providing demand response services. In this paper, a high resolution and granular domestic energy consumption model is applied, which uses a four-node electrical analogue to represent the thermal characteristics of domestic dwellings. Then the performance of an EHP cluster coupled with dwellings is simulated. A control algorithm is designed to match the clusters electric load with renewable generation profile. Recognising the potentially detrimental effect of EHP flexibility exploitation on end-user thermal comfort, the loss of comfort level of occupants is assessed. The possibility of significant thermal discomfort from renewable generation matching is demonstrated.
\end{abstract}

Keywords-flexibility; power-to-heat; EHP; renewable energy; demand response

\section{INTRODUCTION}

The Paris agreement agreed in December 2015 would introduce a plan to force all ratifying countries to make their contributions and ensure that the global temperature rise remains "well below $2^{\circ} \mathrm{C}$ " on pre-industrial levels [1]. To this end, electricity may play a more important role in the future, as transportation and heating/cooling sectors are electrified. However, over $40 \%$ of global electricity is still generated by conventional coal-fired power plants with a high emission factor [2]. Therefore, in order to achieve a low-carbon energy system, the decarbonisation of electricity should be achieved by increasing the integration of renewable energy generation.

Among different renewable generation technologies, solar photovoltaic (PV) and wind turbines have experienced the fastest expansion. These technologies, account for $67.7 \%$ of new renewable generating capacity around world in 2014 [3]. However, because of the uncertain and volatile nature of wind and solar resources, the increasing penetration level of renewable energy sources (RES) creates challenges to reliable power system operation. In addition, more frequent curtailments of wind and solar generation can be expected due to the mismatch of renewable generation and demand. One potential solution for these issues is to consider a paradigm change in electricity consuming/generating behaviour, from "production pursuing demand" to "demand pursuing generation" [4].

Energy consumption can be categorized into four sectors: industrial, transport, services and domestic. Domestic demand accounts for $29 \%$ of final energy consumption in UK [5]. Within the UK domestic sector, $80 \%$ of the energy consumption is used for space and water heating [5]. Moreover, based on the projection of National Grid (the GB system operator) in the Gone Green scenario, UK families may possess 9 million EHPs by 2030, which would transfer a part of heating energy consumption from gas to electricity [6]. Due to the thermal inertia of dwellings and domestic hot water (DHW) tanks, the flexibility embedded in the electric demand of domestic heating can be utilised to reduce RES curtailment. References [7], [8] proposed an optimal EHP control method to maximize the cost benefit in individual dwellings with a PV array and domestic wind generation. In [9], the operation of a cluster of distributed energy resources (DERs) is modelled, which included micro-combined heat and power, storage, electric vehicles, etc. This paper has designed a power matching algorithm to match the demand profile with an offshore wind generation profile in order to reduce the curtailment of wind energy. However, none of current publications have applied any high resolution and granular model to simulate the performance of EHPs with this power match mechanism. Nevertheless, the comfort loss of occupants is neglected during this power match process, which would be a crucial factor for the feasibility of this algorithm in a residential community. Therefore, this paper applies a oneminute resolution domestic energy consumption model to simulate the performance of a cluster of dwellings. The operation of a heating unit is considered as controllable, while the baseload (e.g., electrical appliances and lighting) of the dwelling is acknowledged as inflexible. The whole energy consumption profile of the dwellings cluster is constrained to match with two separate renewable generation profiles which is originate from a wind farm and a PV plant. Thermal discomfort that results from this renewable energy matching is quantified, as are self-sufficiency and self-consumption metrics.

The remainder of this paper is structured as follows: Section II introduces the model used in the simulation and the metrics used to assess the performance of a buildings cluster. Section III explains the assumptions and scenario information applied in the simulation. Section IV details the simulation results of the case studies and Section V concludes the paper and proposes possible directions for future work. 


\section{Methodology}

\section{A. Domestic energy consumption model}

The load profile of domestic dwellings is simulated with a domestic energy consumption model introduced in [10]-[12]. The energy consumption profile is at one-minute resolution, which gives the possibility to capture the thermal dynamics of the heating system and dwellings in great detail. In addition, the operation and states of heating units, thermal storage and building are all modelled with physically-based electrical analogues. In particular, a four-node electrical analogue is used to mimic the thermal states of each building's structure. The model generates the load profile from five different demand types, which are space heating, DHW, lighting, appliances and cooking. In this context, space heating and DHW demands are considered to be "flexible" depending on the comfort level satisfaction of dwelling's occupants.

\section{B. Generation matching contol}

A centralised 'generation match algorithm' is proposed in this paper and used to manipulate the operation of electric heater to coincide with renewable generation at one-minute resolution, which can maximise the consumption of renewable generation. The flowchart of generation matching control algorithm is shown in Fig.1. When a mismatch between renewable generation and the total electric demand is detected (referred as "larger" and "smaller" in Fig.1), the algorithm randomly selects EHPs from the cluster and turns these EHPs on/off to increase or reduce the demand until the difference between the generation and demand reaches an acceptable error range. The value of the error range is set to few kilo watts based on the nominal power rating of an EHP. In practice, there can be a communication delay between renewable plant site and community, which requires the algorithm to use forecasted output of renewable plants to determine the aggregated demand of consumers. Therefore, a certain level of discrepancy between renewable generation and cluster consumption can be expected, but this is out of the scope of this paper.

\section{Performance metrics}

The performance of the central control algorithm is firstly assessed in terms of the quantity of energy supplied directly between the renewable generator and the cluster. This quantity of 'self-supply' energy can be expressed in two ways, as shown in [13], [14]. Firstly, it can be expressed as a proportion of total energy generation, defined by the percentage of selfconsumption metric $\left(\mathrm{Per}^{\text {self con }}\right)$ in equation (1). Secondly self-supply can be represented with respect to the total load, defined by the percentage of self-sufficiency metric (Per self suf $)$, as shown in equation (2). In equation (3), the total electric demand of a dwelling $\left(P_{t}^{\text {dwelling }}\right)$ is calculated with baseload of the dwelling $\left(P_{n, t}^{\text {Base }}\right)$, the electrical input power rating of an EHP $\left(P_{n, t}^{E H P}\right)$, the operation state of an EHP $\left(u_{n, t}^{E H P}\right)$ and the input power of electrical auxiliary heater $\left(P_{n, t}^{A u x}\right)$. $P_{n, t}^{E H P}$ and $u_{n, t}^{E H P}$ are determined based on the hysteresis control logic given in [10]. The instant output power of renewable plant is denoted by $P_{t}^{R E S}$. The start and end times of the generation matching period are given by $T_{\text {Start }}$ and $T_{\text {End }}$ respectively.
To quantify the impacts of control algorithm on comfort level of occupants, the metric percentage dwelling discomfort (PDD) is also defined in (4) below. This describes the probability that the inside temperature $\left(T_{n, t}^{i n}\right)$ of a dwelling during the algorithm application period is outside the normal business as usual $(\mathrm{BaU})$ temperature range of $16.5^{\circ} \mathrm{C}-21.5^{\circ} \mathrm{C}$, as defined in (5).

$$
\begin{aligned}
& \operatorname{Per}^{\text {self con }}(\%)=\frac{\sum_{T^{\text {Start }_{+}}}^{T^{\text {End }}} \min \left\{P_{t}^{R E S}, P_{t}^{\text {dwelling }}\right\}}{\sum_{T^{\text {Start }}+1}^{T_{1} \text { sid }} P_{t}^{R E S}} \\
& \operatorname{Per}^{\text {self suf }}(\%)=\frac{\sum_{T}^{T_{\text {Start }}{ }_{+1}} \min \left\{P_{t}^{R E S}, P_{t}^{\text {dwelling }}\right\}}{\sum_{T}^{T^{\text {End }}} \text { start }_{+1} P_{t}^{\text {dwelling }}} \\
& P_{t}^{\text {dwelling }}=\sum_{n=1}^{N}\left(u_{n, t}^{E H P} \cdot P_{n, t}^{E H P}+P_{n, t}^{A u x}+P_{n, t}^{\text {Base }}\right) \\
& P D D(\%)=100 \times \frac{\sum_{t=T^{\text {Start }}+1}^{T^{\text {End }}}\left(\sum_{n \in N} \alpha_{n, t}\right)}{N \cdot\left(T^{\text {End }}-T^{\text {Start }}\right)} \\
& \alpha_{n, t}=\left\{\begin{array}{ccc}
1 & \text { for } & T_{n, t}^{i n}>21.5 \text { or } T_{n, t}^{i n}<16.5 \\
0 & \text { otherwise }
\end{array}\right.
\end{aligned}
$$

\section{CASE STUDY}

The considered dwelling cluster is composed of 100 modern semi-detached dwellings (built between 1944 and 1984). The temperature profile is derived from the database given in [15] and a typical Manchester, UK winter weekday is selected. The simulation time-series is over six days to help evaluate the effectiveness and the cumulative impacts of the generation matching algorithm. Each dwelling is equipped with a gas boiler or an air source heat pump (ASHP) as the primary heating unit. The ASHP's nominal power rating is calculated to be $4 \mathrm{~kW}$, given the design conditions detailed in [15]. A $10 \mathrm{~kW}$ auxiliary electric heater can also be installed based on the assumption given in the scenarios. A radiator heat emitter is selected, which is the most common emitter type in UK. The volume of the DHW tank is 145 litres, while a 1,000 litres space heating buffer is considered as an optional component. A number of studies have been carried out to demonstrate the capacity of the ASHPs cluster to follow the generation profile from different renewable energy technologies. Wind and solar generation profiles have been taken data with a resolution of 10 minutes from two sites in the UK during winter and scaled to approximately match the total electricity demand from the dwelling cluster with ASHPs over the duration of the six-day simulation period. This scaling has resulted in a $0.27 \mathrm{MW}$ wind turbine and $2.3 \mathrm{MW}$ solar PV plant being chosen. The significant difference in capacity is due to wind having a much greater capacity factor than solar PV in winter. Clusters with and without the presence of a buffer tank and auxiliary have also been simulated to explore the potential for thermal storage to absorb generation and maintain comfort levels. 


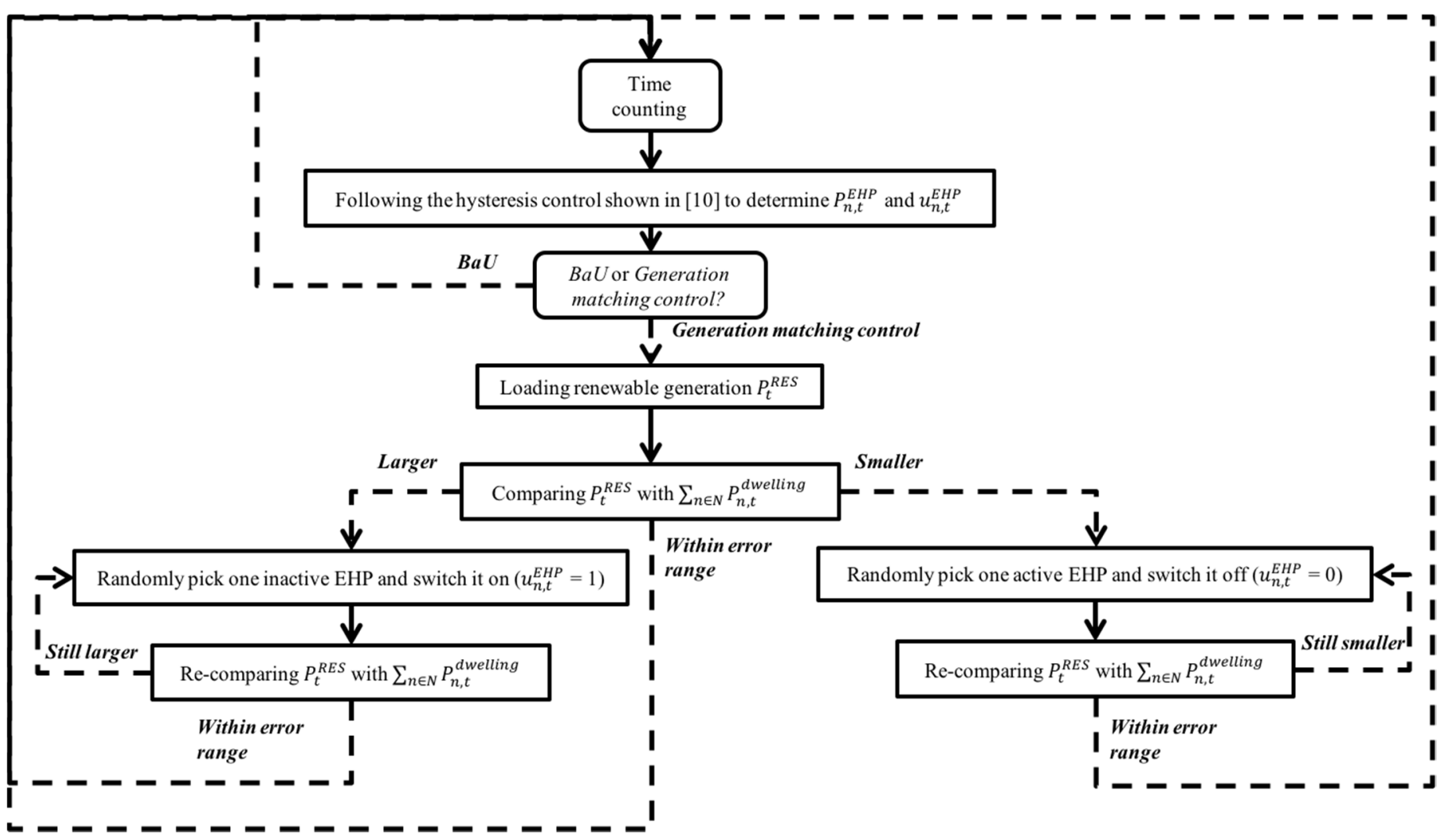

Fig.1 Flow chart of generation matching contol algorithum for EHP cluster.

\section{A. Wind generation}

To explore how generation matching control can increase the level of self-supply compared with implementing gas boiler or ASHP units coupled with wind generation without control, three different cluster types have been simulated:

\section{1) Wind.A:Gas boiler cluster (BaU)}

The first cluster consists of only gas boiler heating, which means that there is only baseline electric load for appliances lighting and cooking. Gas heating is the most common source of heating in the UK, so this scenario represents typical load profiles found today.

\section{2) Wind.B:ASHP cluster}

The second cluster consists of ASHP heated dwellings but without generation matching control. This means that there is a significant increase in electricity consumption but no shifting of demand to match wind generation. This scenario reflects UK government ambitions to electrify domestic heating, but does not capture the potential benefits of flexible heating.

3) Wind.C:ASHP cluster with generation matching control

The third scenario consists of dwellings heated by ASHP units which operate in the centralised generation matching control mode. This scenario represents the potential benefits which can be derived by using the thermal inertia of domestic dwellings to match renewable generation.

The reason for choosing these scenarios is to test the marginal benefit, in terms of self-supply, of adoption either electric heating or 'smart' electric heating compared with baseline conditions (i.e., gas boiler heating).

\section{B. Solar PV}

A 2.3MW solar PV plant can be coupled with the dwellings cluster to satisfy domestic energy consumption. The BaU case is adoption of ASHP without control (PV.A). Then the impact of the generation matching control is considered (PV.B). As the solar generation is concentrated in the daytime, there can be a significant mismatch between solar generation and heat demand, which can lead to substantial electricity import in the evening. Therefore, in case PV.C, a space heating buffer can be introduced to satisfy the peak heat demand at night. In addition, the output power of PV plant can be much higher than the aggregated power rating of ASHP cluster. Thus, auxiliary heaters are also introduced to increase the renewable generation self-consumption rate of the cluster. In summary, the three scenarios are:

- $\quad$ PV.A: BaU ASHP clusters

- PV.B: ASHP clusters with generation matching control

- PV.C: ASHP clusters with buffer, auxiliary heater and generation matching control

The main purpose of the Solar PV case studies is to explore the impacts of generation matching algorithm on dwelling temperature and to demonstrate the potential benefits of increasing the capacity and thermal inertia of the heating system in order to balance renewable generation. 


\section{RESULtS}

\section{A. Wind generation}

To begin with the cluster has been simulated to match generation from a $0.27 \mathrm{MW}$ wind turbine. Fig. 2 shows the load profiles and inside temperatures in the Wind.C scenario. It can be seen that demand perfectly matches generation providing that generation exceeds demand, since the maximum ASHP heating load of the cluster $(\sim 0.4 \mathrm{MW})$ exceeds the maximum generation capacity $(0.27 \mathrm{MW})$. During a few short periods the cluster needs to import electricity, since baseload exceeds generation. This means for the Wind.C case achieves 95\% selfsufficiency, or in other words only $5 \%$ of the cluster's demand needs to be imported from the network.

The impact of the generation matching control algorithm on comfort level is significant. ASHP units without this control (i.e. the Wind.B scenario) PDD is just $1.8 \%$, meaning that on average nearly all dwelling remain within the temperature range $16.5^{\circ} \mathrm{C}$ to $21.5^{\circ} \mathrm{C}$. However, PDD rises to $18 \%$ when the cluster is in the Wind.C scenario, mostly as a result of under heating during periods of low wind output, when average inside temperature drops to a minimum of $14.9^{\circ} \mathrm{C}$.

Fig.3 shows the electricity flows (import, export and selfsupply) for all three scenarios. The quantities of these flows are quantified in Table I, along with the self-supply and discomfort metrics. For the Wind.A scenario, self-sufficiency is $80 \%$, since there is no electric heating load so wind generation can meet demand most of the time. However, this reduced heating load also leads to significant electricity export, resulting a $21 \%$ self-consumption level. In contrast, the ASHP cluster in the Wind.B scenario achieves a $61 \%$ level of self-sufficiency and $69 \%$ self-consumption due to increased load of the cluster and reasonably high coincidence between load and generation. When generation matching control is introduced, as seen in the Wind.C scenario, the level of self-consumption increases to $100 \%$, since the ASHP units can be switched on until generation power in met. Self-consumption is $95 \%$ in this example, since for short periods electricity must be imported to meet base-load $\left(P_{n, t}^{B a s e}\right)$ when this exceeds wind generation.

\section{B. Solar PV}

The second case study demonstrates the use of thermal energy storage and auxiliary electric heater to capture and store the electricity from solar generation for later use.

Fig.4 to Fig.6 below show the load profiles and average inside temperatures of the cluster for the three solar PV scenarios. The main power flows and temperature impacts are also quantified for all three scenarios in Table II below.

Fig.4 shows the BaU case, consisting of the solar PV system and cluster of ASHPs operating independently. It can be seen that there is weak coincidence between load and generation profiles, leading to low levels of self-consumption and self-sufficiency of around $20 \%$. In the PV.B case, the ASHP loads are dispatched to match generation. However, since the ASHP capacity $(\sim 0.4 \mathrm{MW})$ is much smaller than the solar capacity $(\sim 2.3 \mathrm{MW})$, often solar generation exceeds the maximum heating load and electricity is exported. This means the cluster without auxiliary heaters is only able to achieve
$35 \%$ self-consumption. Further, during the evening there are long periods without generation when there is a high baseload and this results in a self-consumption of $66 \%$. The outcome of

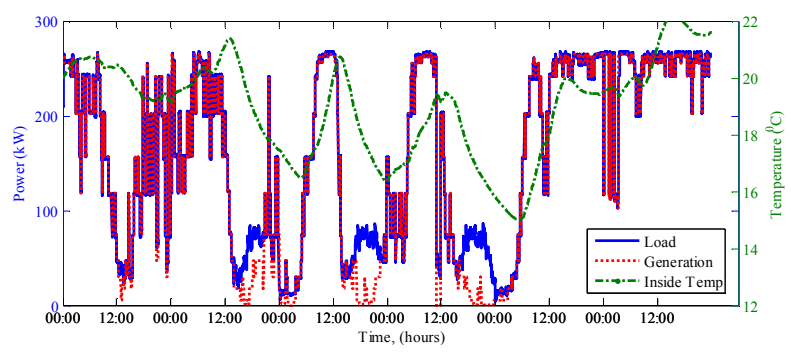

Fig.2 Generation, demand and average inside temperature profiles of Wind.C case.
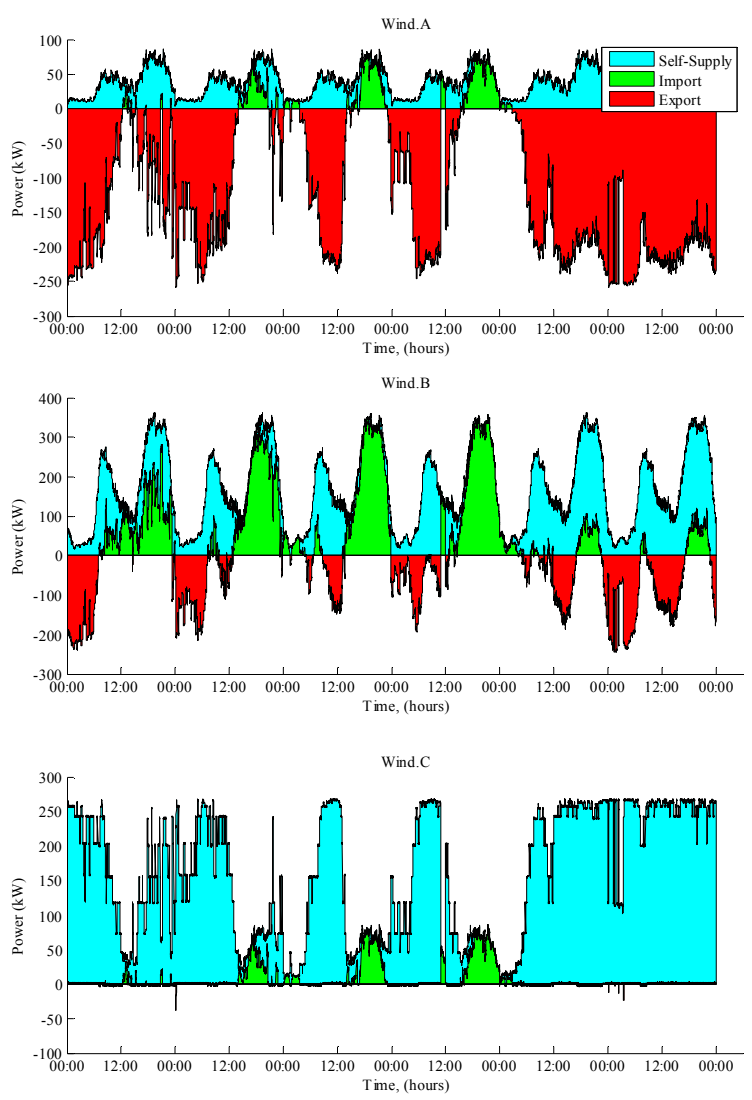

Fig.3 Electricity flows of the cluster with wind generation cases Wind.A, Wind.B and Wind.C

TABLE I. WIND GENERATION IN THREE SCENARIOS.POWER FLOWS AND TEMPERATURE IMPACTS FOR A CLUSTER WITH 0.27 MW WIND PLANT FOR THREE SCENARIOS

\begin{tabular}{|c|c|c|c|}
\hline & Wind.A & Wind.B & Wind.C \\
\hline Demand (MWh) & 56 & 246 & 230 \\
\hline Generation (MWh) & 218 & 218 & 218 \\
\hline Imported (MWh) & 11 & 95 & 12 \\
\hline Export (MWh) & 173 & 67 & 0 \\
\hline Self-supply (MWh) & 45 & 151 & 218 \\
\hline $\operatorname{Per}^{\text {self con }}(\%)$ & $21 \%$ & $69 \%$ & $100 \%$ \\
\hline$P_{e r}^{\text {self suf }}(\%)$ & $80 \%$ & $61 \%$ & $95 \%$ \\
\hline PDD (\%) & $1.5 \%$ & $1.8 \%$ & $18 \%$ \\
\hline
\end{tabular}




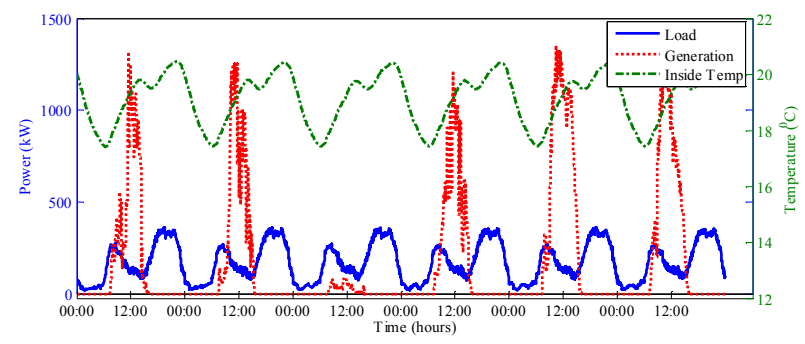

Fig.4 Generation, demand and average inside temperature of PV.A case.

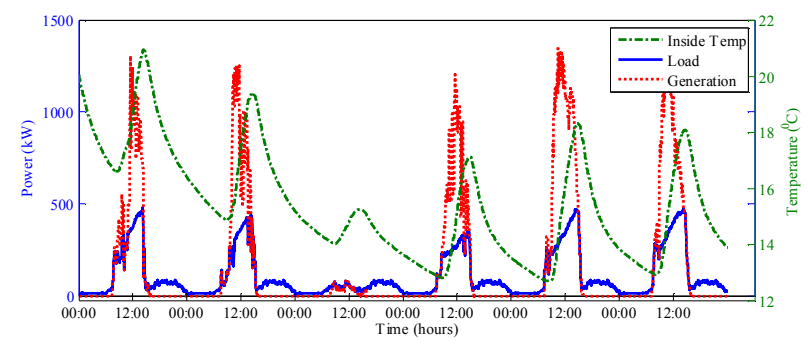

Fig.5 Generation, demand and average inside temperature of PV.B case.

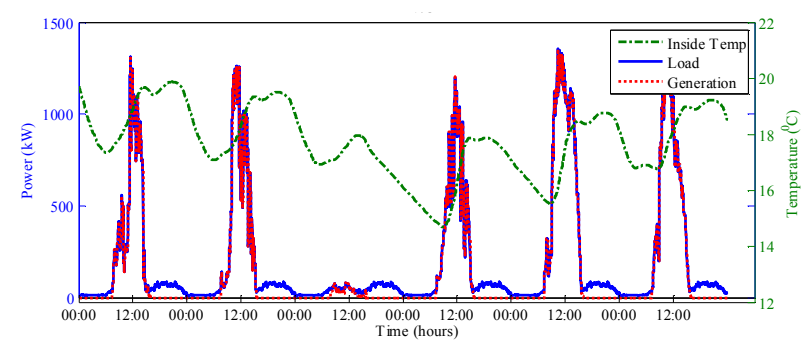

Fig.6 Generation, demand and average inside temperature of PV.C case.

TABLE II. POWER FLOWS AND TEMPERATURE IMPACTS FOR A CLUSTER WITH 2.3 MW SOLAR PV PLANT FOR THREE SCENARIOS

\begin{tabular}{|l|l|l|l|}
\hline & \multicolumn{1}{|c|}{ PV.A } & \multicolumn{1}{c|}{ PV.B } & \multicolumn{1}{c|}{ PV.C } \\
\hline Demand (MWh) & 246 & 133 & 289 \\
\hline Generation (MWh) & 251 & 251 & 251 \\
\hline Imported (MWh) & 198 & 45 & 38 \\
\hline Export (MWh) & 203 & 163 & 1 \\
\hline Self-supply (MWh) & 48 & 88 & 250 \\
\hline Per self con (\%) & $19 \%$ & $35 \%$ & $100 \%$ \\
\hline Per ${ }^{\text {self suf }}(\%)$ & $20 \%$ & $66 \%$ & $86 \%$ \\
\hline PDD (\%) & $1.8 \%$ & $70 \%$ & $16 \%$ \\
\hline
\end{tabular}

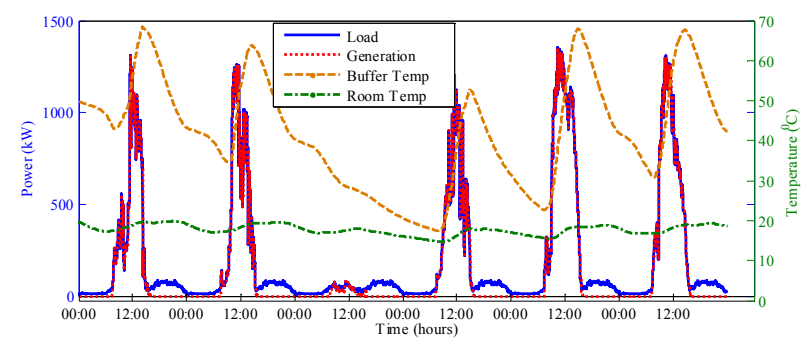

Fig.7 Generation, demand, average inside and buffer temperature profiles of PV.C case.

this is that average ASHP load is reduced compared with the PV.A scenario and this causes a steady decline in inside temperature throughout the simulation period. PDD in the
PV.B scenario is $70 \%$ which is almost entirely caused by no heat supply after sunset, as solar generation is zero during this period. This means that on average $70 \%$ on dwellings have inside temperature below $16.5^{\circ} \mathrm{C}$.

In contrast, Fig. 5 shows the load profile, inside temperature and buffer temperature for the cluster in the PV.C scenario. It can be seen that in this case all solar generation can be absorbed by the cluster since auxiliary heaters are activated when solar output exceeds the maximum ASHP capacity. This increases the level of self-consumption to a maximum of $100 \%$. Self-sufficiency is also increased to $86 \%$ due to increased load during generation periods, with the same requirement for electricity imports to meet baseload when there is not sufficient solar generation as seen in the PV.B scenario. Further, in this case the dwellings are kept within a much more acceptable temperature range, with PDD reduced to $18 \%$. This is because the auxiliary heater is able to absorb sufficient solar generation to meet average heating demand and the buffer tank increases the thermal inertia of the heating system, which enables better balancing of electricity supply with and heating demand throughout the day. This effect is most clear during the evening peak, when the additional thermal inertia of the buffer allows inside temperature to be maintained throughout the evening period, providing there has been sufficient solar generation during the day. For the PV.B case there is on average a $2.2^{\circ} \mathrm{C}$ drop in inside temperature between $4 \mathrm{pm}$ (around sunset) and $8 \mathrm{pm}$, whilst for the PV.C scenario this figure is reduced to $0.1^{\circ} \mathrm{C}$, as shown in Fig.6 .

Fig. 7 below also shows the load profiles and temperatures of the PV.C case, only this time with the inclusion of average buffer temperature. On average each buffer tank absorbs around $25 \mathrm{kWh}$ of thermal energy between sunrise and sunset, resulting in a temperature range of $17^{\circ} \mathrm{C}-69^{\circ} \mathrm{C}$ throughout the simulation period. Whilst this temperature range is within the technical operating limits of such systems, there are likely to be health and safety issues, such as Legionnaires' disease, resulting from the hot water system temperatures going below $45^{\circ} \mathrm{C}$ for extended periods of time [16].

\section{CONCLUSION}

This paper has applied a high resolution and granular model [10] to simulate the performance of electric heat pumps in various scenarios. The effectiveness of centralized control algorithm is discussed, whose aim is to adjust the operation of dwellings' electric heater and match the total domestic electricity consumption with a given renewable generation profile at community level. The paper also assessed the impact of generation matching control on the comfort level of occupants, which is vital for the practical deployment of the algorithm. The results firstly suggest that this control introduced above drastically increases the discomfort level of occupants in both wind and solar PV generation cases, although solar case has experienced a worse discomfort percentage increase to $70 \%$ comparing with $18 \%$ in wind case. However, the impact of generation matching control on comfort level can be mitigated by integrating a buffer and auxiliary heater to increase the thermal inertia of dwelling. Future work aims at developing more robust control with predictive intelligence in order to minimise the impact of the 
algorithm on comfort level of occupants when balancing renewable generation. Additionally, future work can be carried out to capture high resolution coincidences between renewable generation and load profiles in the model. Finally, the seasonal impacts on load following capability should also be explored to understand the year-round potential for this form of control.

\section{REFERENCES}

[1] European Commission, "Paris Agreement," 2015. [Online]. Available: $\mathrm{http} / /$ ec.europa.eu/clima/policies/international/negotiations/paris/index en.htm.

[2] International Energy Agency, "Electricity production from coal sources (\% of total)," 2013. [Online]. Available: http://data.worldbank.org/indicator/EG.ELC.COAL.ZS.

[3] REN21, Renewables 2015-Global Status Report, vol. 4, no. 3. 2015.

[4] D. Six, J. Desmedt, D. Vahnoudt, and J. Bael, "Exploring the flexibility potential of residental heat pumps combined with thermal energy storage for smart grids," in 21th International Conference on Electricity Distribution, 2011, no. 442.

[5] Department for Bussiness Energy \& Industrial Stratergy, "Energy Consumption in the UK," 2016.

[6] National Grid, "UK Future Energy Scenarios," 2014.

[7] S. Sichilalu, T. Mathaba, and X. Xia, "Optimal control of a wind-PVhybrid powered heat pump water heater," Appl. Energy, 2015.
[8] E. M. Wanjiru, S. M. Sichilalu, and X. Xia, "Optimal control of heat pump water heater-instantaneous shower using integrated renewablegrid energy systems," Appl. Energy, 2016.

[9] P. MacDougall, C. Warmer, and K. Kok, "Mitigation of wind power fluctuations by intelligent response of demand and distributed generation," IEEE PES Innov. Smart Grid Technol. Conf. Eur., 2011.

[10] N. Good, L. Zhang, A. Navarro-Espinosa, and P. Mancarella, "High resolution modelling of multi-energy domestic demand profiles," Appl. Energy, vol. 137, pp. 193-210, Jan. 2015.

[11] N. Chapman, L. Zhang, N. Good, and P. Mancarella, "Exploring flexibility of aggregated residential electric heat pumps," in 2016 IEEE International Energy Conference (ENERGYCON), 2016, pp. 1-6.

[12] L. Zhang, N. Good, A. Navarro-Espinosa, and P. Mancarella, "Modelling of household electro-thermal technologies for demand response applications," in IEEE PES Innovative Smart Grid Technologies, Europe, 2014, pp. 1-6.

[13] R. Luthander, J. Widén, D. Nilsson, and J. Palm, "Photovoltaic selfconsumption in buildings: A review," Appl. Energy, vol. 142, pp. 80-94, 2015.

[14] S. Cao, A. Hasan, and K. Sirén, "Matching analysis for on-site hybrid renewable energy systems of office buildings with extended indices," Appl. Energy, vol. 113, pp. 230-247, Jan. 2014.

[15] Chartered Institute of Building Services Engineers, Environmental Design: CIBSE guide A, 7, illustr ed. CIBSE, 2006.

[16] UK Health and Safety Executive, "Legionnaires ' disease," Approv. Code Pract. Guid. Regul., vol. L8, 2013. 